\title{
Estratégias de InClusão Escolar: A EduCaÇão \\ Física e as práticas esportivas do Projeto \\ SeMEar no Caic do Vale do Sol de \\ Araraquara-SP
}

Fábio Tadeu Reina*

Luci Regina Muzzeti**

Maria Beatriz Loureiro de Oliveira**

Maria José Romanatto***

Artur Carmello Neto****

\section{Resumo}

Este artigo examina o potencial da disciplina Educação Física no processo de inclusão escolar de alunos provindos das camadas populares na escola periférica Emef Ricardo C.C. Monteiro, popularmente apelidada de Caic do Vale do Sol, por estar localizada no bairro Vale do Sol, em Araraquara-SP. A partir de entrevistas com agentes envolvidos na instituição, levantaram-se os dados que comprovam a importância da disciplina Educação Física e do projeto SEMEAR como estratégias de manutenção da permanência do discente no espaço escolar e as consequências positivas dessa inclusão. Por tratar-se de uma pesquisa de caráter sociológico, foram utilizados estudos de Pierre Bourdieu e colaboradores, em que suas categorias de análise sociológica garantem o suporte necessário para verificar a reestruturação do habitus primário dos alunos, adquirido no seio familiar, em habitus cultivado pela escola, para que haja a aceitação dos códigos simbólicos impostos pela instituição escolar e legitimados pela sociedade. Conclui-se que a Educação Física, disciplina obrigatória do currículo escolar, desempenha um papel fundamental nessa instituição escolar e, principalmente, para as famílias pertencentes a essa fração de classe que, consciente ou inconscientemente, atribuem a ela (Educação Física) a longevidade do percurso escolar de sua prole, possibilitando assim uma melhor qualidade de vida.

\footnotetext{
*Doutor em Educação Escolar - Unesp-Araraquara-SP.

**Professoras-doutoras do Departamento de Didática - Unesp-Araraquara-SP.

***Doutoranda em Educação Escolar - Unesp-Araraquara-SP.

****Mestrando em Educação Escolar - Unesp-Araraquara-SP. E-mail: netoartu@ bol.com.br.
} 
Palavras-chave: Educação Física; Projeto SEMEAR; Inclusão discente; Estratégias; Habitus.

\section{INTRODUÇão}

Este artigo é voltado para a temática da Educação Física escolar e pretende mostrar o potencial de inclusão da disciplina em relação aos alunos das camadas populares, por dar início à reestruturação do habitus de aceitação dos valores impostos pela escola. Entende-se por inclusão, neste artigo, a permanência dos alunos das camadas populares na escola, para garantir a sua longevidade escolar.

O interesse em analisar a Educação Física no espaço escolar decorre da relevância que essa disciplina vem ganhando nos últimos tempos. Segundo Daólio (1994), existe uma grande valorização e aceitabilidade dessa disciplina pelos alunos em detrimento de outras áreas do conhecimento escolar.

Este estudo apresenta uma perspectiva sociológica, com base nos estudos de Pierre Bourdieu e seus colaboradores, pois suas categorias de análise permitem desenvolver um quadro teórico que evidencia os fatores que, de alguma forma, influem nas disposições assimiladas pelos alunos no interior da escola, principalmente por meio da disciplina Educação Física.

Bourdieu afirma que a relação dos agentes com as práticas esportivas, ou com a disciplina aqui estudada, depende do conteúdo cultural herdado pelos alunos no seio das famílias. Essa herança cultural é definida como o conjunto de conhecimentos, saberes, informações, atitudes, disposições, códigos linguísticos e posturas, responsáveis pelas escolhas dos esportes, pela valorização que os alunos atribuem a essas práticas esportivas e também pelo êxito e fracasso que experimentam na escola. Em suma, pela relação dos diversos agentes como mundo simbólico.

Salienta-se que o projeto SEMEAR e a Educação Física não são desvinculados, mas tratados pelos professores e alunos dessa escola municipal como se fossem uma só e mesma coisa. Conforme o documento analisado, o projeto de esportes do SEMEAR, logo na sua introdução, no parágrafo II, informa que "tem como pretensão romper com os paradigmas tradicionais das aulas de Educação Física, procurando atingir a democracia e a qualidade de trabalho sem qualquer tipo de exclusão"(2004, p.1).

Apontar alguns paradigmas se torna relevante, pois o texto do projeto não trouxe tal esclarecimento; pontuá-los, então, poderá facilitar o entendimento da proposta pedagógica da escola. Ressaltamos ainda que a intenção não é fazer nenhuma análise mais profunda dos paradigmas, já que este artigo não objetiva os momentos históricos da Educação Física. 
A intenção é apenas, como já dito, tentar esclarecer melhor a quebra de paradigmas que o projeto SEMEAR se propõe a fazer, na tentativa de alcançar a democracia preconizada nos Parâmetros Curriculares Nacionais (PCN), especificamente na área de Educação Física.

\section{Metodologia}

Para realizar este estudo se optou por realizar uma revisão bibliográfica, onde foram apontadas as características específicas da Educação Física ao longo de diversos momentos históricos, a fim de verificar os paradigmas vigentes dessa área do conhecimento, determinantes para a elaboração de conteúdos importantes a serem trabalhados pelos professores de Educação Física no âmbito escolar.

Após essa etapa, para verificar se haveria ou não a inclusão dos alunos provenientes das camadas populares no espaço escolar, com a Educação Física como meio para esse processo, realizaram-se as entrevistas entre os professores. Os depoimentos foram gravados e transcritos na íntegra, corrigindo-se apenas os erros de português.

Para este estudo foram selecionadas as falas da coordenadora pedagógica, aqui identificada pela letra G. A medida foi tomada para preservar sua integridade, conforme orientação do comitê de ética.

\section{BreVe Síntese do histórico da Educação Física}

De acordo com Oliveira (2002), a Educação Física escolar, até décadas atrás, apresentava um modelo em que o físico (corpo), a aptidão física e o desempenho eram o mais importante, desprezando muitas vezes os aspectos sociais, cognitivos e afetivos. O relevante nas aulas de Educação Física escolar era o Esporte-Rendimento, ou seja, o aluno deveria apresentar um bom desempenho e habilidades não só nas aulas, mas também nos jogos e em determinadas modalidades esportivas, fato que levava o aluno a ser quase um atleta.

Dessa forma, a Educação Física escolar apresentava um modelo excludente, por apresentar aulas com métodos que, caracterizados por repetição, tornavamo ensino monótono e indiferente à participação de todos os alunos.

$\mathrm{Na}$ tentativa de superar os paradigmas mencionados, a escola, por meio da Educação Física, mais especificamente do projeto SEMEAR, poderá oferecer condições para a inclusão dos alunos provindos das camadas populares no espaço escolar.

A inclusão deverá ocorrer pela mudança de comportamentos dos alunos, por meio da intervenção dos professores, durante a aplicação dos conteúdos específicos da Educação Física desenvolvidos nas aulas. 


\subsection{A Educação Física e o projeto SEMEAR}

A origem do nome do projeto resulta do verbo SEMEAR que, segundo Ferreira (1985) traz, o seguinte significado: 1. Deitar semente de, para que germinem. 2. Espalhar, propalar. 3. Causar, ocasionar. No caso do projeto, a ideia foi justamente a de lançar uma sementinha para a germinação de novas expectativas educacionais na área de Educação Física, ou seja, uma efetiva participação da disciplina no processo educacional da escola.

Associou-se à ideia central de lançar uma sementinha a criatividade de atribuir a cada letra do verbo SEMEAR um significado, relativo a condições perceptíveis na prática cotidiana das atividades físicas: o S vem de Saúde; o E, de Educação; o M, de movimento; o segundo E, de Esporte; o A, de Ação; e, por fim, o R, de Recreação.

"O projeto SEMEAR possui este nome por tratar-se de uma sementinha lançada na escola para oferecer às crianças da comunidade escolar oportunidades de praticar atividades esportivas, além das aulas regulares de Educação Física. Nesse sentido, busca favorecer a inclusão social, através das práticas esportivas. Pois a convivência diária facilita a integração, a prática de valores como, por exemplo: respeito, fraternidade, honestidade, etc. (Profa. G, coordenadora do projeto SEMEAR)."

A ideia de implantar o projeto na escola surgiu de uma visita à cidade de Catanduva (SP), mais especificamente no Centro de Atendimento Integral da Criança (Caic) da Escola Municipal de Ensino Fundamental (Emef) Profa. Graciema Ramos da Silva, onde funciona um projeto chamado "ESCOLA VIVA", em que as crianças desenvolvem atividades esportivas e culturais, permanecendo na escola em período integral. De um lado são desenvolvidas atividades esportivas, como futebol de salão, futebol de campo, basquetebol, handebol, voleibol, vôlei de areia, recreação, condicionamento físico, atletismo, damas, xadrez e ginástica olímpica; de outro, atividades culturais, como teatro, dança, coral, oficinas de flautas, capoeira e exposições plásticas.

Segundo a coordenadora do projeto SEMEAR:

"Motivados com essa visita e com o funcionamento desse projeto, nos propusemos a realizar um projeto semelhante, levando-se em consideração nossa realidade e o espaço físico que temos aqui na escola (Profa. G)."

De acordo com seu depoimento, foi fundamental o empenho da direção da escola 
na implantação do projeto SEMEAR, coma intervenção direta da diretora da escola (profa. MariaAlice) junto à Secretaria Municipal de Educação, para que o projeto pudesse tornar-se uma realidade.

Em suas palavras:

"Vejo que a facilidade de ter o projeto aqui na nossa escola diz respeito, primeiro, ao fato de a direção da escola ser muito favorável em relação à Educação Física, incentivando os professores a buscar fontes diferentes para trabalhar a Educação Física aqui no Caic do Vale do Sol (Profa. G.)."

O projeto SEMEAR funciona em período contrário às aulas regulares dos outros componentes curriculares. Diferentemente do projeto da cidade de Catanduva (SP), em que as crianças ficam na escola em período integral, em Araraquara (SP), na Emef Ricardo de C. C. Monteiro, elas saem de suas casas para irem à escola participar do projeto.

"O ideal é que a criança ficasse o tempo integral na escola, mas isso não é possível. A infraestrutura da escola não comporta esse acúmulo de crianças nos dois períodos letivos, pois não temos recursos humanos para cuidar dessas crianças até o início das aulas e das atividades na escola, nem merenda suficiente para atender a todas as crianças ao mesmo tempo, nem chuveiros suficientes para um banho, nem locais apropriados para um possível descanso (Profa. G.)."

Mesmo coma dificuldade apresentada para que ocorra a permanência das crianças em período integral na escola, o primeiro e mais importante objetivo proposto no projeto SEMEAR - que é propiciar às crianças o maior tempo possível na escola, para criar maiores laços de amizade, respeito, solidariedade, noções de cidadania, entre outros - está mantido, como prevê a proposta pedagógica da escola.

Outros objetivos do projeto SEMEAR, embasados na proposta pedagógica da escola (2004, p.02), são:

$\checkmark$ Tornar a escola atraente;

$\checkmark$ Oferecer atividades próprias para cada idade;

$\checkmark$ Descobrir talentos;

$\checkmark$ Desenvolver habilidades esportivas;

$\checkmark$ Desenvolver o respeito por si e pelos outros; 
$\checkmark$ Desenvolver motricidade;

$\checkmark$ Combater o trabalho infantil.

Quanto ao educando, o projeto SEMEAR pretende que ele:

$\checkmark$ Participe de atividades corporais e de relações equilibradas e construtivas com os outros, respeitando as características físicas próprias e dos colegas;

$\checkmark$ Tenha atitudes de respeito mútuo, dignidade e solidariedade em situações lúdicas e esportivas;

$\checkmark$ Desfrute de manifestações culturais de nosso país e do mundo, integrando pessoas de diferentes habilidades sociais;

$\checkmark$ Adote hábitos saudáveis de higiene e de alimentação e de atividades corporais, fazendo a manutenção e a melhoria da saúde coletiva;

$\checkmark$ Solucione problemas de ordem corporal, regulando e dosando o esforço com a faixa etária, aperfeiçoando o desenvolvimento de maneira saudável e equilibrada;

$\checkmark$ Reconheça diversos padrões de beleza estética corporal que existem nos diferentes grupos sociais, analisando os padrões divulgados pela mídia, evitando o consumismo e o preconceito.

Cabe à escola, segundo o projeto SEMEAR, realizar os objetivos um e dois:

1 - Reconhecer condições de trabalho que comprometam o processo de crescimento e desenvolvimento, reivindicando condições de vida dignas;

2 - Organizar e intervir no espaço de forma autônoma, reconhecendo as necessidades básicas do ser humano e os direitos dos cidadãos, reivindicando lugares adequados para atividades físicas e lazer.

Para alcançar todos esses objetivos, o projeto SEMEAR está estruturado da seguinte forma:

"Ao todo somos sete professores de Educação Física, todos com nível superior e todos efetivos por aprovação em concurso público municipal; nos damos superbem uns com os outros e com os demais professores das outras disciplinas. Sempre sentamos para conversar, além dos dias de HTPC (Horário de Trabalho Pedagógico coletivo), pois sentimos a necessidade, diante dos acontecimentos que vão surgindo durante o dia a dia. Damos o máximo de nós para poder atender às necessidades das crianças (Profa. G.)."

\section{Resultados e discussões}

Na escola pública, há vários fatores que contribuem para com a degeneração da qualidade de ensino. Entre eles se observa a tendência de diminuição no quadro 
docente efetivo das escolas e do aumento do número de professores admitidos em caráter temporário (ACT), (Paro, 1996, p. 237). No Caic do Vale do Sol essa realidade se inverte, pois os sete professores são efetivos, apresentando, portanto, qualificação profissional exigida (formação acadêmica superior na área de Educação Física). Por serem efetivos, estão dispostos a incorporar a carreira acadêmica, comprometidos com o papel que desempenham na instituição e imbuídos do objetivo de oferecer um ensino de qualidade, que atenda aos interesses da comunidade local. Cabe ressaltar que este ponto é um diferencial importante na constatação da qualidade de ensino proporcionada pela Educação Física nesta escola em relação às outras do ensino público.

A carga horária diária de trabalho dos professores de Educação Física do Caic do Vale do Sol mostra que eles não trabalham no mesmo período; estão divididos entre o período da manhã e o da tarde. Mas todas as modalidades esportivas presentes no projeto SEMEAR são oferecidas tanto num período, quanto no outro. São elas: voleibol, basquetebol, futebol de salão, futebol de campo, handebol, atletismo, ginástica, tênis de mesa, xadrez e dança. Tais atividades são desenvolvidas duas vezes por semana, em aulas duplas de 50 minutos.

"O material esportivo é muito bom, proporcionando a nós, professores, darmos boas aulas. Temos aqui na escola todo o material esportivo que solicitamos para realizar o projeto de maneira eficaz; ou seja, 50 bolas de basquete, 50 bolas de voleibol, 50 bolas de handebol, 50 bolas de futebol de campo, 50 bolas de futebol de salão, 100 bolas de borracha, 50 cones de borracha, 60 cordas individuais de sisal, 200 arcos bambolês, 50 bastões, 60 colchonetes para ginástica, colchão para salto em altura, redes de voleibol, redinhas de basquete, redes de futebol de campo e de salão, enfim não podemos reclamar do material esportivo (Profa. G)."

Na Emef Ricardo C.C. Monteiro, popularmente chamado Caic do Vale do Sol, as improvisações nas aulas da disciplina Educação Física são raras. Os materiais esportivos são em grande quantidade, como observado no almoxarifado da escola e nos espaços físicos que atendemàs diversas práticas esportivas desenvolvidas no projeto SEMEAR.

"Como já disse anteriormente, o empenho da direção foi fundamental para que tivéssemos todas as condições favoráveis para desenvolvermos o nosso trabalho, uma amostra é esse tanto de material que temos aqui 
na nossa escola. Ela (diretora Maria Alice) adora praticar atividades físicas, tem uma afinidade grande com a Educação física e isso é muito bom para nós (Profa. G).”

Observou-se também que, no Caic do Vale do Sol, os professores de Educação Física têm um tratamento diferenciado em relação ao de outras escolas públicas no que diz respeito a sua formação, pois constantemente participam de cursos de aperfeiçoamento e reciclagem motivados pela direção da escola. A educação continuada dos professores é algo a que a escola dá muita ênfase.

"Já os pais ainda não possuem um envolvimento muito acentuado em relação a querer saber mais sobre o projeto. Pelo que pude observar nas reuniões bimestrais, eles gostam que seus filhos estejam aqui na escola participando das atividades que a escola lhes oferece, mas não existem uma sistemática observação e a participação deles (pais) sobre o que realmente estamos fazendo aqui no projeto SEMEAR com seus filhos (Profa. G)."

Analisando afala acima, pensou-se que, se houvesse uma aproximação maior dos pais com a instituição escolar, o processo de reestruturação do habitus ocorreria mais rápido, pois os pais estariam constantemente intervindo junto a seus filhos, cobrando deles posturas escolares condizentes com o preterido pela escola e considerado legítimo pela sociedade.

"Em compensação, as crianças adoram participar do projeto SEMEAR. Quando a aula está acabando, elas pedem sempre para ficar um pouco mais; somos obrigados a mandá-las embora para suas casas (Profa. G)."

A motivação dos alunos, constatada pela descrição acima, mostra o quanto eles assimilam os conteúdos específicos da área com eficiência, pois alcançam um sucesso que lhes dá muita vontade de permanecer no espaço escolar por mais tempo.

"Os resultados obtidos com elas, quando participam do projeto SEMEAR, são sempre positivos. As crianças que participam do projeto são todas estudantes aqui da escola: hoje estamos atendendo 200 crianças por dia. A criança pode participar de todas as modalidades esportivas oferecidas, não há limite de participação (Profa. G.)." 
A professora G. ressalta a importância do projeto para a mudança do comportamento das crianças. E isso fica explicitado com sua fala:

"Percebo a diferença de comportamento de uma criança que participa do projeto de uma criança que nunca participou, existe uma afinidade muito grande entre nós, professores, e as crianças; elas confiam tanto na nossa pessoa que, se precisar pular num buraco, elas pulam. Para alcançar resultados positivos procuramos, durante as aulas, incutir valores de respeito, de aceitação do colega do jeito que ele é; procuramos inserir todos os alunos nas práticas esportivas sem distinção nenhuma, desde o mais magrinho ao mais gordinho, todos têm o mesmo direito e as mesmas oportunidades aqui na prática das modalidades esportivas. E aqueles que se destacam atleticamente, procuramos torná-lo um líder positivo, ajudando a elevar a autoestima dos outros colegas (Prof. G)."

A professora chama a atenção para o rendimento escolar:

"Outra estratégia que utilizamos aqui é que eles não podem ser bons apenas no esporte, têm que ser bons também nas outras matérias escolares (português, matemática, etc.). Para isso estão sempre em contato com os professores dos demais componentes curriculares; existe um respeito muito grande da parte deles (professores) com a nossa disciplina. Eles reconhecem nosso trabalho como importante aqui no Caic do Vale do Sol (Profa. G)."

Diante dessa realidade, se verificou que a Educação Física é um importante meio para que esses alunos, provenientes das camadas populares, se sintam incluídos no espaço escolar, pois a aproximação com os conteúdos desenvolvidos nas aulas faz com que tenham sucesso e um bom rendimento nessa disciplina, fato constatado no depoimento da professora $\mathrm{G}$.

Mais ainda, o acompanhamento dos professores de Educação Física os incentiva para que consigam ter bons rendimentos também em outras disciplinas da grade curricular e chegar à tal inclusão, entendida neste artigo como a perspectiva da permanência desses alunos no âmbito escolar, para que atinjam uma longevidade na sua trajetória, aumentem o grau de escolaridade e, possivelmente, acumulem capital cultural importante para uma possível ascensão social. 


\section{Considerações Finais}

Do que foi exposto, pode-se inferir que o projeto SEMEAR procura reestruturar seu habitus primário em um habitus determinado pela escola, porque apresenta um sistema de disposições que valoriza o comportamento disciplinado. Isso, de alguma forma, facilita a adaptação do aluno em sala de aula, tornando-o mais obediente, dócil, auxiliando assim na aprendizagem dos conteúdos culturalmente legítimos e socialmente valorizados pela escola e pela sociedade.

\section{REFERÊNCIAS}

BOURDIEU, P. A Economia das Trocas Simbólicas. São Paulo: Perspectivas, 1974a.

BOURDIEU, P. A. Escola conservadora: as desigualdades frente à escola e a cultura. Trad. Aparecida Joly Gouveia. Educação em Revista, Belo Horizonte, n. 10, dez.1989 a, p.3-15.

Coisas ditas. Trad. Cássia R. da Silveira e Denise Moreno Pegorim. São Paulo: Brasiliense, 1990a.

Contrafogos. Trad.Lucy Magalhães.Rio de Janeiro:Jorge Zahar, 1998.

Escritos da Educação. Org.Maria Alice Nogueira e Afrânio Catani. Rio de Janeiro Vozes, 1998.

O poder simbólico. Trad. Fernando Tomaz. Lisboa: Difel, 1989c.

BOURDIEU, P; BOLTANSKI, L; SAINT-MARTIN, M. As estratégias de reconversão: as classes sociais e o sistema de ensino. In: DURAND, J.C. (Org.) Educação e hegemonia de classe. Trad. Maria Alice Machado de Gouveia. Rio de Janeiro: Zahar, 1979b.

BOURDIEU, P.; PASSERON, J.C. A reprodução: elementos para uma teoria do sistema de ensino. Trad. Reynaldo Bairão. Rio de Janeiro: Francisco Alves, 1975.

BRACHT, V. A criança que prática esporte respeita as regras do jogo...

capitalista. In: OLIVEIRA (Org.). Fundamentos Pedagógicos: Educação 
Física. Rio de Janeiro: Ao Livro Técnico, 1987, p.180-190.

A Educação Física escolar como campo de convivência social. Revista Brasileira de Ciências dos Esportes CBCE, Campinas, v.9, n.3, maio 1988, p.23.

BRASIL. Secretaria de Educação Fundamental. Parâmetros Curriculares Nacionais. Brasilia: MEC, 1997.

FERREIRA, V.L.C. Prática de Educação Física no $1 .^{\circ}$ grau; modelo de reprodução ou perspectiva de transformação. São Paulo: IBRASA, 1986.

FREITAG, B. Escola, Estado e Sociedade. 4. ed. São Paulo: Moraes, 1980.

GHUIRALDELLI, P. Educação Física progressista: a pedagogia crítico-social dos conteúdos e a Educação Física brasileira. São Paulo: Edições Loyola, 1988.

LUDKE, M. Entrevista com Pierre Bourdieu: Teoria e Educação, Porto Alegre, n.3, 1991, p.3-8

MEDINA, J.P.S. O brasileiro e o seu corpo: educação e política do corpo. Campinas: Papirus, 1990.

MICELI, S. (Org.). A economia das trocas simbólicas, trad. Sergio Miceli, Silvia de Almeida Prado, Sonia Miceli e Wilson Campos Vieira. São Paulo: Perspectiva, 1974. (Coleção Estudos, 20).

MUZZETI, L.R. Trajetórias escolares de professores primárias formadas em São Carlos nos anos 40, São Carlos: UFSCar. Dissertação (Mestrado) Programa de Pós- Graduação em Educação, Universidade Federal de São Carlos, 1992.

NAREZI, G. Habitus, Educação e reprodução em Pierre Bourdieu. São Carlos: UFSCar,1994. (Datilografado.)

PARO, V. H. Administração escolar: introdução crítica. São Paulo: Cortez, 1996. TANI, G.O. et.al. Educação Física escolar. Fundamentos de uma REVISTA UNIARA, v. 12, n.2, dez. 2009 
abordagem desenvolvimentista. São Paulo: EPU/EDUSP, 1988.

DAÓLIO, Jocimar. A representação do trabalho do professor de Educação Física na escola: Do corpo matéria-prima ao corpo cidadão: São Paulo,USP Dissertação (Mestrado).Programa de Pós-Graduação em Educação Física Universidade de São Paulo, 1994.

TARDIF, M. Saberes Docentes e Formação Profissional. Petrópolis: Vozes, 2002.

SECRETARIA MUNICIPALDE EDUCAÇÃO. Plano Municipal de ensino, 2001.

Title: School InClusion Strategies: Physical Education and Sport Practices in Projeto Semear at Caic Vale do Sol de Araraquara (SP)

\section{ABSTRACT}

This paper examines the potential of Physical Education discipline in the process of school inclusion of students from the lower working classes in a peripherical elementary school EMEF Ricardo C. C. Monteiro, popularly known as CAIC Vale do Sol, because of its location in the section of the city of Araraquara, SP, named as Vale do Sol ( Sun Valley). The data, obtained from interviews with people of the institution, confirmed the importance of the discipline Physical Education and of the Project SEMEAR as strategies for maintaining the continuity of the students' presence at school and the positive consequences of this inclusion. Considering the sociological character of this research, the studies of Pierre Bourdieu and followers offered the categories of sociological analysis which ensured the necessary support to verify the restructuring of the primary habitus of the students acquired in their families in a habitus cultivated in school, to assure the acceptance of symbolic codes imposed by the educational institution and legitimized by society. We can conclude that Physical Education as a compulsory subject in school curriculum plays a key role in this educational institution and especially to those families belonging to this class fraction that consciously or unconsciously ascribe to it (Physical Education) the continuity of the school trajectory of their children, making possible a better quality of life.

KEYwords: Physical Education; Project SEMEAR; Student Inclusio; Strategies; Habitus. 